\title{
Total thoracoscopic ablation in patients with atrial fibrillation and left ventricular dysfunction
}

Hye Ree Kim, MD, ${ }^{a}$ Dong-Seop Jeong, MD, PhD, ${ }^{b}$ Hee-Jin Kwon, MD, ${ }^{a}$ Seung-Jung Park, MD, PhD, ${ }^{a}$ Kyoung-Min Park, MD, PhD, ${ }^{a}$ June Soo Kim, MD, $\mathrm{PhD},{ }^{\mathrm{a}}$ and Young Keun $\mathrm{On}, \mathrm{MD}, \mathrm{PhD}^{\mathrm{a}}$

\section{ABSTRACT}

Objective: To evaluate the effectiveness and safety of totally thoracoscopic ablation (TTA) in patients with left ventricular (LV) dysfunction for treatment of atrial fibrillation (AF) refractory to antiarrhythmic drug (AAD) therapy.

Methods: Between January 2012 and December 2018, 31 patients underwent TTA with drug-refractory AF and preoperative left ventricular ejection fraction (LVEF) $<50 \%$ were included. Of the 31 patients, 8 received additional catheter ablation with an electrophysiologic study within 3 months after TTA. The rhythm outcome was obtained by 12-lead electrocardiography or 24-hour Holter monitoring.

Results: The patient cohort had a mean age of $54.9 \pm 9.0$ years and consisted of $51.6 \%$ with persistent $\operatorname{AF}(n=16), 45.2 \%$ with long-standing persistent $\operatorname{AF}(n=14)$, and $3.2 \%$ with paroxysmal $\operatorname{AF}(n=1)$. No patients died during the follow-up period. Compared with baseline, mean postoperative LVEF at 3 months (interquartile range [IQR], 2-6 months) increased significantly (from $39.7 \pm 6.1 \%$ to $53.6 \pm 9.3 \%$; $P<.001$ ). At 25 months (IQR, 14-45 months), LVEF was sustained or further improved (from $39.7 \pm 6.1 \%$ to $58.1 \pm 7.5 \%$; $P<.001$ ). The rate of sinus rhythm state was $93.5 \%$ (29 of 31), and freedom from arrhythmias off AADs after the final procedure was $61.3 \%$ (19 of 31 ) at a median follow-up of 32 months (IQR, 2454 months).

Conclusions: TTA is a safe and effective procedure that improves LV function and restores sinus rhythm in AF patients with LV dysfunction. (JTCVS Techniques 2021;8:60-6)

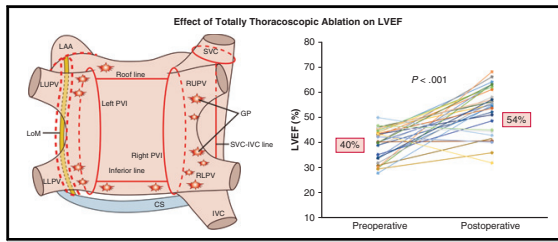

Improvement of left ventricular ejection fraction following totally thoracoscopic ablation.

CENTRAL MESSAGE

Minimally invasive surgical ablation through a thoracoscopic approach is safe and effective in improving left ventricular function and restoring sinus rhythm.

\section{PERSPECTIVE}

Totally thoracoscopic ablation (TTA) can be considered as an alternative to catheter ablation to improve outcomes in patients with left ventricular (LV) dysfunction for atrial fibrillation (AF) refractory to antiarrhythmic drugs. We evaluated the safety and effectiveness of TTA in patients with AF and LV dysfunction.

See Commentaries on pages 67 and 69 . $\longrightarrow$ Video clip is available online.

From the a Division of Cardiology, Department of Internal Medicine, Heart, Vascular and Stroke Institute and ${ }^{\mathrm{b}}$ Department of Thoracic and Cardiovascular Surgery, Samsung Medical Center, Sungkyunkwan University School of Medicine, Seoul, Republic of Korea.

Drs Kim and Jeong contributed equally to this work and should be considered co-first authors.

Received for publication April 2, 2021; accepted for publication April 7, 2021; available ahead of print April 20, 2021.

Address for reprints: Young Keun On, MD, PhD, Division of Cardiology, Department of Internal Medicine, Samsung Medical Center, Heart, Vascular, and Stroke Institute, Sungkyunkwan University School of Medicine, 81 Irwin-ro, Gangnam-gu, Seoul 06351, Republic of Korea (E-mail: yk.on@samsung.com).

2666-2507

Copyright $\odot 2021$ Published by Elsevier Inc. on behalf of The American Association for Thoracic Surgery. This is an open access article under the CC BY-NC-ND license (http://creativecommons.org/licenses/by-nc-nd/4.0/).

https://doi.org/10.1016/j.xjtc.2021.04.006
Atrial fibrillation (AF) and heart failure (HF) share multiple risk factors and pathophysiology. ${ }^{1-3}$ In a global AF registry, the rates of $\mathrm{HF}$ were $33 \%$ in paroxysmal $\mathrm{AF}, 44 \%$ in persistent $\mathrm{AF}$, and $56 \%$ in permanent $\mathrm{AF},{ }^{1}$ and the rates of both $\mathrm{HF}$ and coexisting AF continue to increase. Regardless of which comes first, patients with concomitant HF and AF have been associated with synergistically worse symptoms and poorer outcomes. ${ }^{3,4}$ Finding effective rhythm control therapies for these patients is important given that the maintenance of sinus rhythm has been associated with decreased mortality and HF hospitalization. ${ }^{5}$

Totally thoracoscopic ablation (TTA) for patients with drug-refractory or failed prior catheter ablation $\mathrm{AF}$ with class $2 \mathrm{~A}$ indication has evolved rapidly. ${ }^{6-9} \mathrm{~A}$ randomized clinical trial showed that thoracoscopic surgical ablation was superior to catheter ablation in achieving freedom from $\mathrm{AF} .{ }^{10}$ However, the adverse events associated with 

Abbreviations and Acronyms
$\mathrm{AAD}=$ antiarrhythmic drug
$\mathrm{AF}=$ atrial fibrillation
ECG = electrocardiography
$\mathrm{GP}=$ ganglionated plexus
$\mathrm{HF}=$ heart failure
$\mathrm{IQR}=$ interquartile range
$\mathrm{LA}=$ left atrium/atrial
$\mathrm{LV}=$ left ventricle/ventricular
$\mathrm{LVEF}=$ left ventricular ejection fraction
$\mathrm{PV}=$ pulmonary vein
TTA $=$ totally thoracoscopic ablation

surgical ablation seem to be more frequent than those associated with catheter ablation. ${ }^{11,12}$

To date, there have been few reports investigating the effectiveness and safety of TTA in AF patients with left ventricular (LV) dysfunction. ${ }^{9}$ In the present study, we evaluated sinus rhythm maintenance, changes in echocardiographic parameters, and complications in patients with LV dysfunction undergoing TTA for treatment of drug-refractory AF.

\section{METHODS}

\section{Study Population}

This registry study enrolled 31 consecutive patients who underwent TTA with drug-refractory AF and impaired LV systolic function (LV ejection fraction $[\mathrm{LVEF}]<50 \%$ ) at our medical center between January 2012 and December 2018. All patients had a recent ( $<6$ months) assessment of LVEF with a transthoracic echocardiogram before surgery. Before an indication for TTA, failure of antiarrhythmic drugs (AADs) in controlling the symptoms of AF or maintaining sinus rhythm had to be documented. Definitions of paroxysmal, persistent, and longstanding persistent AF were based on the Heart Rhythm Society, European Heart Rhythm Association, and European Cardiac Arrhythmia Society consensus statement. ${ }^{8}$ The center's Institutional Review Board approved the study protocol and publication of data (2020-09-034-001; September 10, 2020), and patients provided informed written consent for the publication of their study data.

\section{Surgical Procedure}

At our institution, "totally thoracoscopic" is defined as a video-assisted thoracoscopic surgical technique without the aid of cardiopulmonary bypass or the Da Vinci robotic system. This technique is performed via 3 holes (two 5-mm ports and one 10-mm port) bilaterally. Starting on the right side, a $5-\mathrm{mm}$ port is introduced into the fourth intercostal space at the mid-axillary line. Carbon dioxide insufflation is used to expand the operative field and depress the diaphragm. The remaining 2 ports are placed in the third intercostal space at the anterior axillary line and in the sixth intercostal space at the mid-axillary line. After pericardial tenting, a lighted dissector (Lumitip Dissector, AtriCure, Cincinnati, Ohio) is used to pass a rubber band under the pulmonary vein (PV) antrum through the oblique sinus. Then a clamp (Isolator Transpolar Clamp; AtriCure) is connected to the rubber band and positioned around the PV antrum.

$\mathrm{PV}$ antrum isolation is performed by 6 applications of bipolar radiofrequency energy to the clamps around the PV antrum. To prevent macro-reentry, additional superior and inferior ablation lines connecting both PV isolation lines are created epicardially using a linear pen device (AtriCure). Confirmation of ablation lines is performed via pacing testing using the AtriCure Colltip pen. This procedure is repeated on the left side.

Ganglionated plexuses (GPs) are subsequently ablated in the epicardial fat pad anterior side of the right superior and inferior PVs, the inferior side of the right inferior PV, and the left atrial (LA) posterior wall. On the left side, GPs in the fat pads on the LA roof, medial to the left superior PV and inferior side of the inferior PV, are also identified and ablated. High-frequency stimulation is used at ablation, and its response is defined as a $\geq 50 \%$ increase in the $R-R$ interval. Using a bipolar ablation pen (Isolator Transpolar pen; AtriCure), highfrequency stimulation is delivered (cycle length, $60 \mathrm{~ms} ; 16 \mathrm{~Hz}$; pulse width, $1.0 \mathrm{~ms}$ ) in output increments from 1 to $25 \mathrm{~mA}$. When highfrequency stimulation does not evoke a vagal response, ablation is performed on the basis of anatomic landmarks. Additional GP ablation is performed when necessary.

After PV and GP ablation, the ligament of Marshall is dissected and ablated. Once all ablation is completed and the conduction block is confirmed, the LA appendage is removed using an Echelon Flex 60 articulating endoscopic linear stapler (Ethicon Endo-Surgery, Cincinnati, Ohio) (Figure 1 and Video 1).

\section{Electrophysiologic Study Procedure}

An electrophysiologic study was performed within 3 months after TTA in 8 patients who were documented with typical atrial flutter before or during admission for TTA. For each patient, a duo-decapolar catheter was placed into the right atrium and coronary sinus, and a quadripolar catheter was placed into the right ventricle apex. After positioning the catheters, access to the LA was achieved through a standard transseptal puncture using the Brockenbrough technique. Lasso catheters were inserted into the PVs, and their potentials were checked. Three-dimensional reconstructions of the LA and PVs were created using the CARTO 3 system (Biosense Webster, Diamond Bar, Calif). Image integration with computed tomography scans was performed.

\section{Postoperative Care and Follow-up}

Following TTA, all patients were monitored for the first 24 hours in the intensive care unit. After pericardial effusion was excluded by transthoracic echocardiography, heparin infusion was started 4 hours after surgery and titrated according to the activated partial thromboplastin time (target between 60 and 80 seconds). The day after the procedure, oral anticoagulation (warfarin or non-vitamin $\mathrm{K}$ antagonist oral anticoagulant) was started. In the absence of contraindication, AADs were continued after surgery.

An early event was defined as an event that occurred within the first 30 postoperative days, and all later events were defined as late events. Early events included stroke, sinus node dysfunction, bleeding, and other major adverse events associated with TTA. In cases of persistent postoperative AF during admission, at least one attempt was made to restore sinus rhythm via electrical cardioversion.

All patients were followed up at 2 weeks, 3 months, 6 months, and every 6 months thereafter. At each visit, 12-lead electrocardiography (ECG) or 24-hour Holter monitoring was performed to evaluate rhythm and atrial activity. Recurrence was defined as symptomatic or asymptomatic episodes of AF lasting longer than 30 seconds and identified on 12-lead ECG or 24-hour Holter monitoring after a blanking period of 3 months. When the rhythm was stable and restoration of both atrial activities was confirmed, AADs were discontinued at 3 months or up to 6 months. Sinus rhythm off AADs was defined as freedom from AF with discontinuation of AADs for at least 12 months. LVEF was assessed by transthoracic echocardiography. 


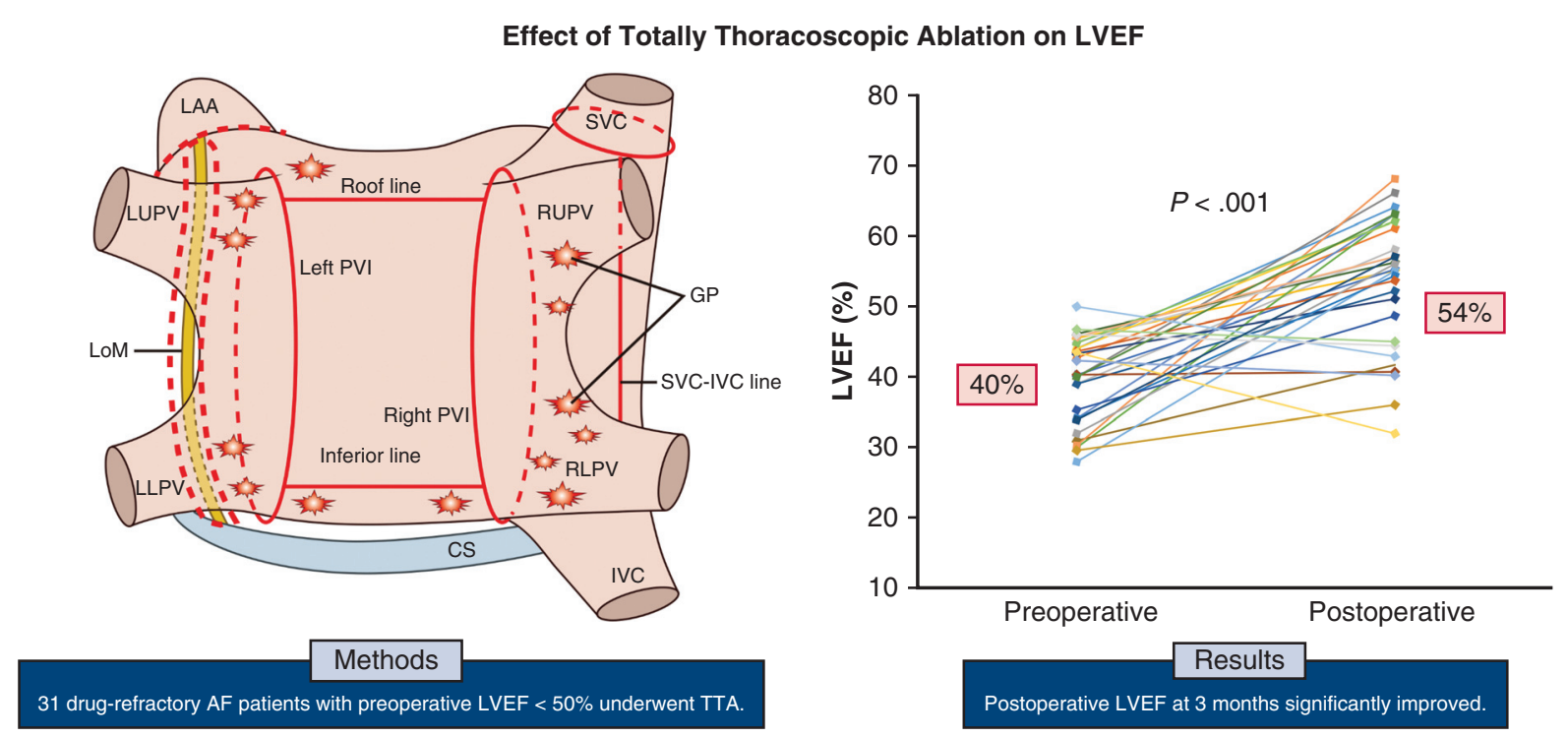

Conclusion: TTA is an effective procedure that improves LVEF in AF patients with left ventricular dysfunction.

TTA, totally thoracoscopic ablation; $L V E F$, left ventricular ejection fraction; $A F$, atrial fibrillation; $L A A$, left atrial appendage; $L U P V$, left upper pulmonary vein; $L L P V$, left lower pulmonary vein; RUPV, right upper pulmonary vein; RLPV, right lower pulmonary vein; $P V I$, pulmonary vein isolation; LoM, ligament of Marshall; GP, ganglionated plexus; SVC, superior vena cava; IVC, inferior vena cava; CS, coronary sinus.

FIGURE 1. Left, schematic illustration of surgical ablation lesion. Right, improvement of left ventricular function in patients with left ventricular ejection fraction $(L V E F)<50 \%$ at a median of 3 months following totally thoracoscopic ablation. The mean LVEF improved from $39.7 \pm 6.1 \%$ to $53.6 \pm 9.3 \%$ $(P<.001)$. $L A A$, Left atrial appendage, $S V C$, superior vena cava; $L U P V$, left upper pulmonary vein; $R U P V$, right upper pulmonary vein; $P V I$, pulmonary vein isolation; $G P$, ganglionated plexus; $L O M$, ligament of Marshail; $I V C$, inferior vena cava; $L L P V$, left lower pulmonary vein; $R L P V$, right lower pulmonary vein; $C S$, coronary sinus; $A F$, atrial fibrillation; $T T A$, totally thoracoscopic ablation.

\section{Statistical Analysis}

All statistical analyses were performed using SPSS version 25.0 (IBM, Armonk, NY). Baseline data are presented as frequency or mean \pm standard deviation. The duration of follow-up is presented as median and interquartile range (IQR). Continuous variables were compared using Student's $t$ test, and categorical variables were compared using the $\chi^{2}$ test. All tests were 2 -sided, and a $P$ value $<.05$ was considered statistically significant.

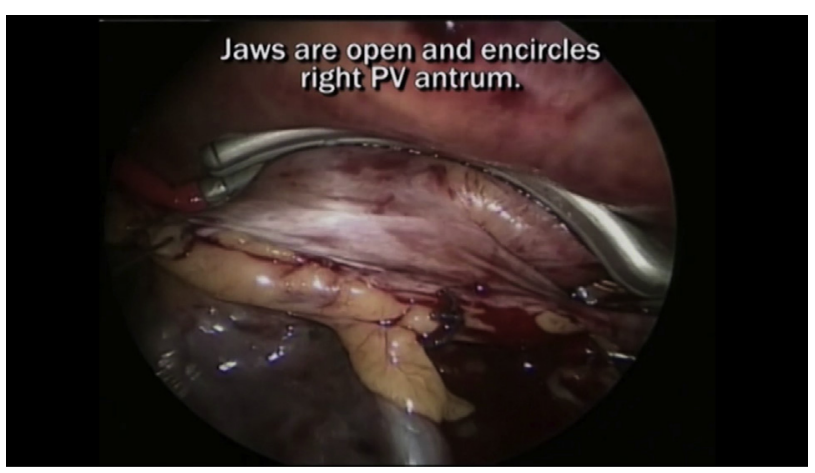

VIDEO 1. Minimally invasive surgical atrial fibrillation ablation through a thoracoscopic approach. Video available at: https://www.jtcvs.org/ article/S2666-2507(21)00298-4/fulltext.

\section{RESULTS}

\section{Patient-Related Characteristics}

Between July 20, 2012, and 28 December 2018, 31 patients $(90.3 \%$ male; mean age, $54.9 \pm 9.0$ years) with impaired LV systolic function (mean LVEF at baseline, $39.6 \pm 6.1 \%$ ) underwent TTA. The baseline characteristics of these patients are summarized in Table 1 . The cohort consisted of 16 patients with persistent AF $(51.6 \%), 14$ patients with long-standing persistent AF (45.2\%), and 1 patient with paroxysmal AF.

Bilateral PV epicardial isolation was performed in all patients. The LA appendage was resected in all but 1 patient $(96.8 \%)$. The reason for not excluding the LA appendage was that the LA was small with severe LV systolic dysfunction (LVEF, 28\%). Eight patients who had documented typical atrial flutter before or during admission for TTA underwent additional radiofrequency catheter ablation on cavotricuspid isthmus. PV potential was checked, and PV isolation was confirmed in all 8 patients. Thoracoscopic and postoperative electrophysiologic procedural data are shown in Table 2.

\section{Echocardiographic Outcomes}

All patients in this analysis had at least 2 recorded echocardiograms. Compared with baseline, LVEF was 
TABLE 1. Baseline patient characteristics $(N=31)$

\begin{tabular}{|c|c|}
\hline Characteristic & Value \\
\hline Age, $y$, mean $\pm \mathrm{SD} ;$ range & $54.9 \pm 9.0 ; 37-75$ \\
\hline Male sex, n (\%) & $28(90.3)$ \\
\hline $\mathrm{BMI}, \mathrm{kg} / \mathrm{m}^{2}$, mean $\pm \mathrm{SD}$; range & $27.4 \pm 2.9 ; 22.2-33.1$ \\
\hline Hypertension, n (\%) & $17(54.8)$ \\
\hline Diabetes mellitus, n (\%) & $3(9.7)$ \\
\hline Prior stroke, n (\%) & $5(16.1)$ \\
\hline Prior PCI, n (\%) & $2(6.5)$ \\
\hline Chronic kidney disease, n (\%) & $1(3.2)$ \\
\hline Thyroid disease, $\mathrm{n}(\%)$ & $2(6.5)$ \\
\hline $\begin{array}{l}\text { Duration of } \mathrm{AF} \text {, mo, mean } \pm \mathrm{SD} \text {; } \\
\text { range }\end{array}$ & $55.5 \pm 55.5 ; 3-242$ \\
\hline \multicolumn{2}{|l|}{ Type of AF, n (\%) } \\
\hline Paroxysmal & $1(3.2)$ \\
\hline Persistent & $16(51.6)$ \\
\hline Long-standing persistent & $14(45.2)$ \\
\hline $\begin{array}{l}\mathrm{CHA}_{2} \mathrm{DS}_{2} \text {-VASc score } \\
\text { mean } \pm \mathrm{SD} ; \text { range }\end{array}$ & $2.2 \pm 1.3 ; 1-6$ \\
\hline Prior catheter ablation, n (\%) & $7(22.6)$ \\
\hline \multicolumn{2}{|c|}{$\begin{array}{l}\text { Echocardiographic findings, mean } \pm \mathrm{SD} \text {; } \\
\quad \text { range }\end{array}$} \\
\hline LA volume index, $\mathrm{mL} / \mathrm{m}^{2}$ & $50.5 \pm 17.1 ; 29.7-92.6$ \\
\hline LA diameter, $\mathrm{mm}$ & $45.2 \pm 7.4 ; 34.0-64.6$ \\
\hline LVEF, \% & $39.6 \pm 6.1 ; 28.0-49.9$ \\
\hline $\begin{array}{l}\text { Follow up duration, mo, median } \\
\text { (IQR); range }\end{array}$ & 32 (24-54); 6-96 \\
\hline
\end{tabular}

$S D$, Standard deviation; $B M I$, body mass index; $P C I$, percutaneous coronary intervention; $A F$, atrial fibrillation; $\mathrm{CHA}_{2} D S_{2}-V A S c$, congestive heart failure, hypertension, age, diabetes, prior stroke or transient ischemic attack or thromboembolism, vascular disease, and female sex; $L A$, left atrium; $L V E F$, left ventricular ejection fraction; $I Q R$, interquartile range.

significantly increased at 3 months (IQR, 2-6 months) postoperatively (from $39.7 \pm 6.1 \%$ to $53.6 \pm 9.3 \% ; P<.001$ ) (Figure 1). Eight patients who underwent additional catheter ablation underwent follow-up echocardiography before the procedure.

At the last follow-up echocardiogram (at a median of 25 months; IQR, 14-45 months), LVEF was sustained or further improved (from $39.7 \pm 6.1 \%$ to $58.1 \pm 7.5 \% ; P<.001)$. Two patients did not show an improvement in LVEF; one of these patients had an implanted permanent pacemaker due to sick sinus syndrome with a long duration of AF prior to TTA, and the other patient had an LA volume index of $89.3 \mathrm{~mL} / \mathrm{m}^{2}$, the most dilated LA in this series. In addition, a relative decrease in LA volume index, with no statistically significant difference, was observed during the last follow-up period (from $50.5 \pm 17.1$ to $46.2 \pm 15.1 ; P=.060$ ) (Table 3).
TABLE 2. Procedure characteristics $(\mathbf{N}=31)$

\begin{tabular}{lc}
\hline \multicolumn{1}{c}{ Characteristic } & Value, $\mathbf{n}(\%)$ \\
\hline Thoracoscopic procedures & $31(100)$ \\
PV isolation & $31(100)$ \\
GP ablation & $29(93.5)$ \\
Roof line ablation & $27(87.1)$ \\
Inferior line ablation & $29(93.5)$ \\
Division of ligament of Marshall & $28(90.3)$ \\
LA appendage removed & $30(96.8)$ \\
SVC circular ablation & $12(38.7)$ \\
SVC-IVC linear ablation & $2(6.5)$ \\
Intraoperative sinus conversion & $28(90.3)$ \\
Spontaneous & $14(50.0)$ \\
Cardioversion & $14(50.0)$ \\
Postoperative EPS & $8(25.8)$ \\
Roof line ablation & $1(12.5)$ \\
CTI ablation & $8(100)$ \\
Mitral isthmus ablation & $2(25.0)$ \\
Septal ablation & $1(12.5)$ \\
\hline
\end{tabular}

$P V$, Pulmonary vein; $G P$, ganglionated plexus; $L A$, left atrium; $S V C$, superior vena cava; IVC, inferior vena cava; EPS, electrophysiologic study; CTI, cavotricuspid isthmus.

\section{Rhythm Outcomes}

At a median follow-up of 32 months (IQR, 2457 months), the freedom from atrial arrhythmia was $61.3 \%$ (19 of 31 patients) (Figure 2). AF never recurred in these 19 patients after TTA. With or without additional intervention including catheter ablation or AADs, 93.5\% (29 of 31) of the patients had a sinus rhythm state on ECG or 24-hour Holter monitoring at the last follow-up.

\section{Complications}

No patient died during the procedure or throughout follow-up. No conversions to sternotomy were required. Reoperation was performed in 1 patient because of hemothorax. One patient experienced a minor stroke postoperatively after discontinuation of heparin before starting oral anticoagulation. Sinus node dysfunction was observed in 2 patients, both of whom spontaneously recovered to normal sinus rhythm. Two cases of pulmonary complication were observed, including asthma attack and pulmonary edema. All patients recovered without sequelae. One patient received a permanent pacemaker implantation during follow-up; however, this was not directly related to the thoracoscopic procedure (Table 4).

\section{DISCUSSION}

We present our single-center experience with the potential long-term clinical advantages of minimally invasive thoracoscopic ablation in patients with $\mathrm{AF}$, especially in a subgroup of high-risk patients with LV dysfunction. Our main findings can be summarized as follows: (1) LVEF was significantly increased between baseline and 
TABLE 3. Outcomes of echocardiographic parameters at baseline and follow-up

\begin{tabular}{|c|c|c|c|c|c|}
\hline Parameter & Preoperative & Postoperative & $P$ value & Last follow-up & $P$ value* \\
\hline Follow-up, mo, median (IQR) & & \multicolumn{2}{|c|}{$4.8(2-6)$} & \multicolumn{2}{|c|}{$31.3(16-45)$} \\
\hline $\mathrm{LVEF}, \%$, mean $\pm \mathrm{SD}$ & $39.7 \pm 6.1$ & $53.6 \pm 9.3$ & $<.001$ & $58.1 \pm 7.5$ & $<.001$ \\
\hline LA diameter, mm, mean \pm SD & $45.2 \pm 7.4$ & $46.1 \pm 5.2$ & .285 & $45.4 \pm 5.0$ & .871 \\
\hline $\mathrm{LAVI}, \mathrm{mL} / \mathrm{m}^{2}$, mean $\pm \mathrm{SD}$ & $50.5 \pm 17.1$ & $48.0 \pm 7.1$ & .341 & $46.1 \pm 15.2$ & .060 \\
\hline
\end{tabular}

$I Q R$, Interquartile rang; $L V E F$, left ventricular ejection fraction; $S D$, standard deviation; $L A$, left atrium; $L A V I$, left atrial volume index. *Reference; preoperative value.

postoperative/long term follow-up; (2) the arrhythmia-free off-AAD success rate with a single procedure of TTA was $61.3 \%$ at a median follow-up of 32 months; and (3) the rate of early surgical-related complications was $16 \%$, with no deaths.

There have been few studies reporting the outcomes of minimally invasive surgical ablation using a thoracoscopic approach for patients with LV dysfunction and lone AF. ${ }^{9}$ Several retrospective studies of the Cox-Maze procedure have shown improved LV function after surgical AF ablation in patients with impaired LV function. Stulak and colleagues $^{13}$ from the Mayo Clinic reported improved LVEF immediately after the Cox-Maze III procedure and was sustained at last follow-up (median, 48 months) in 23 patients with persistent $\mathrm{AF}$ and $\mathrm{LV}$ dysfunction. Ad and colleagues $^{14}$ from the Inova Heart Center reported a significant improvement in LVEF, from $30 \pm 5.0 \%$ to $45 \pm 13.0 \%$, at a mean of $1.5 \pm 11.3$ months in 44 patients following the Cox-Maze III/IV procedure. Adademir and colleagues ${ }^{15}$ demonstrated the efficacy of the stand-alone Cox-Maze IV procedure in patients with $\mathrm{AF}$ and $\mathrm{LV}$ dysfunction. We would like to show the efficacy of the thoracoscopic epicardial ablation technique in this population of $\mathrm{AF}$ with $\mathrm{LV}$ dysfunction.

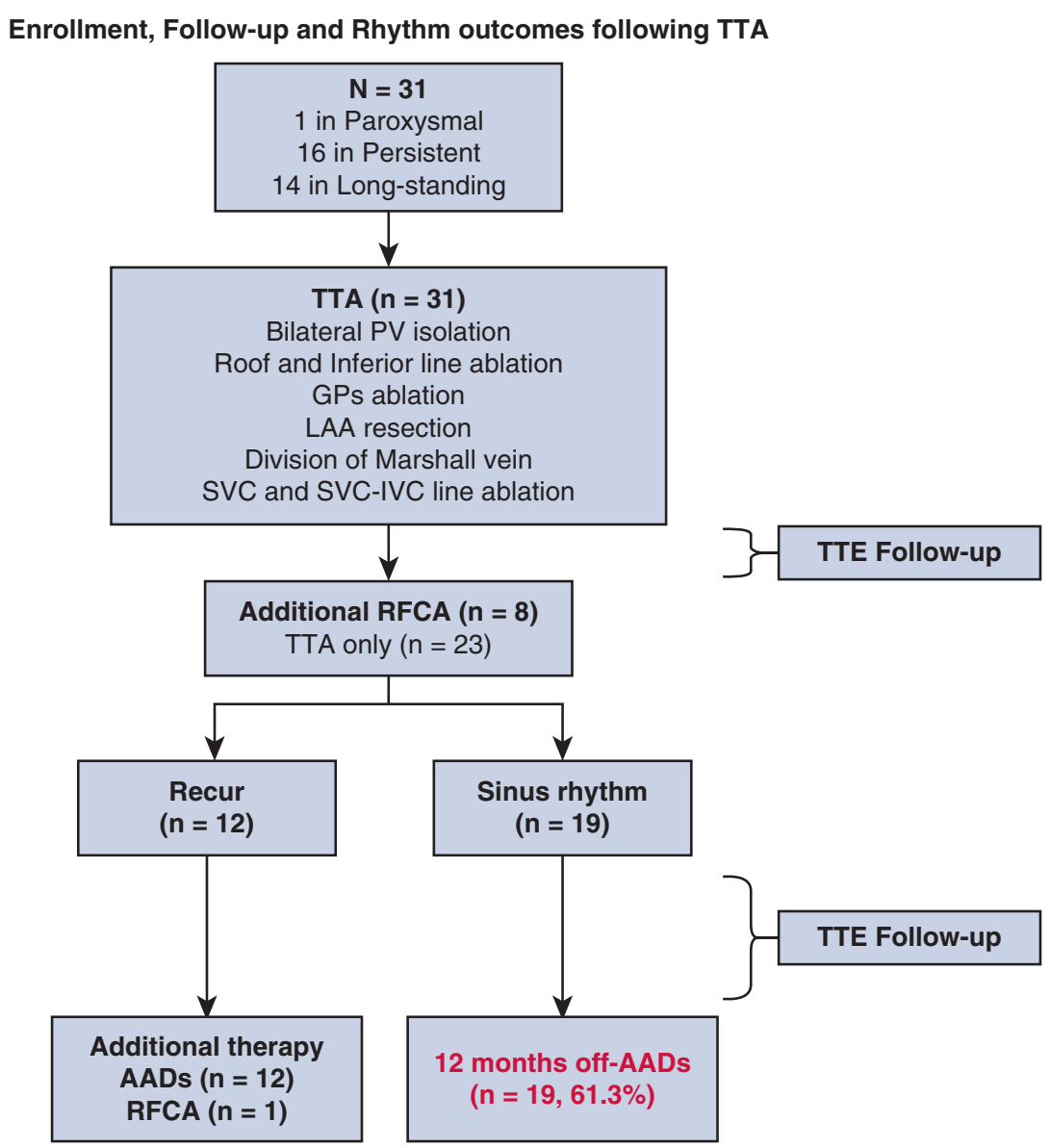

FIGURE 2. Flow diagram of enrollment, follow-up, and rhythm outcomes at a median 32 months following totally thoracoscopic ablation. TTA, Totally thoracoscopic ablation; $P V$, pulmonary vein; $G P$, ganglionated plexus; $L A A$, left atrial appendage, $S V C$, superior vena cava; $I V C$, inferior vena cava; TTE, transthoracic echocardiography; $R F C A$, radiofrequency catheter ablation; $A A D$, anti-arrhythmic drug. 
TABLE 4. Postprocedural complications $(\mathbf{N}=\mathbf{3 1})$

\begin{tabular}{lc}
\hline \multicolumn{1}{c}{ Complication } & Value, $\mathbf{n}(\%)$ \\
\hline Mortality & $0(0)$ \\
Early events & \\
Conversion to surgical procedure & $0(0)$ \\
Hemothorax requiring reoperation & $1(3.2)$ \\
Neurologic complication (minor stroke) & $1(3.2)$ \\
Sinus node dysfunction & $2(6.5)$ \\
Pericardial effusion & $0(0)$ \\
Pulmonary complications & $2(6.5)$ \\
Late events & \\
Pulmonary vein to esophageal fistula & $0(0)$ \\
Neurologic complication & $0(0)$ \\
Pacemaker implantation & $1(3.2)$ \\
Bleeding from anticoagulation & $0(0)$ \\
\hline
\end{tabular}

In $\mathrm{AF}$ patients with $\mathrm{LV}$ dysfunction, restoration of sinus rhythm has several advantages. First, recovery of atrial contraction can result in increased LV filling and cardiac output. ${ }^{16}$ Second, regularity of ventricular response is also associated with increased cardiac output regardless of heart rate. ${ }^{17}$ A previous study demonstrated that irregular ventricular pacing resulted in a $12 \%$ decrease in cardiac output compared with regular ventricular pacing. ${ }^{17}$ Sairaku and colleagues $^{18}$ showed that rate control alone during $\mathrm{AF}$ without sinus conversion may result in incomplete cure of tachycardia-induced cardiomyopathy. Especially in patients with a high probability of recurrence because of abnormal substrates, a reduction in AF burden and restoration of sinus rhythm may contribute to improvement of LV dysfunction and maintenance of cardiac function. ${ }^{14}$ Following recovery of LV function, patients require regular follow-up and monitoring of their individual substrates related to AF recurrence.

In 1 patient, we did not resect the LA appendage because the LA was small with severe LV dysfunction. The LA appendage has several important mechanical functions as a reservoir and due to its intrinsic contractile property. In an in vivo study, LA appendage removal result in decreased LA compliance-associated reservoir function, with subsequent decreased LV filling and diminished cardiac output. ${ }^{19}$ Phan and colleagues ${ }^{20}$ reported significant increases in LA filling pressure and LA size among nonvalvular AF patients after LA appendage closure. Remnant LA appendage could have a positive effect on LV function. Further investigation of the potential effects of LA appendage removal on heart function is needed, especially in patients with $\mathrm{AF}$ and $\mathrm{LV}$ dysfunction.

Our data show a $16 \%$ rate of complications without sequelae, pacemaker requirement, or death. The Atrial Fibrillation Catheter Ablation versus Surgical Ablation Treatment (FAST) Study, ${ }^{10}$ a prospective randomized trial including 120 patients with drug-refractory AF or failed prior catheter ablation, reported a higher success rate but also a higher complication rate after TTA compared with catheter ablation. Surgical ablation is more invasive and carries a higher complication rate than catheter ablation. ${ }^{8,11}$ In a recent randomized trial of catheter ablation versus thoracoscopic surgical ablation in long-standing persistent AF (CASA-AF), thoracoscopic surgical ablation had a $15 \%$ rate of serious complications within 30 days, including 1 death. ${ }^{21} \mathrm{~A}$ systemic safety analysis of TTA found a 30-day postoperative complication rate of $11.8 \%$. ${ }^{9}$ Surgical ablation is part of a growing trend toward less invasive and thoracoscopic approaches, during which complications related to surgery can be expected to decrease.

A $61.3 \%$ arrhythmia-free success rate with a single procedure at a median of 2.6-year follow-up in patients with left ventricular dysfunction is comparable to the results reported after TTA. Previous studies focusing on long-term outcomes after TTA, including hybrid ablation, have reported success rates ranging from $38 \%$ to $83 \%$ for up to 5 years, depending on the AF subtype (paroxysmal or persistent), duration of follow-up, and use of AADs. ${ }^{22-25}$ An observational study found a $60 \%$ overall freedom from $\mathrm{AF}$ at a mean follow-up of $4.0 \pm 0.6$ years in a population with normal LV function. ${ }^{26}$

A single procedure alone cannot perfectly treat $\mathrm{AF}^{27} \mathrm{~A}$ major advantage of TTA is the achievement and maintenance of PV isolation. However, TTA has difficulty accessing cavotricuspid isthmus, septal line, and mitral isthmus lesions. ${ }^{28}$ In previous studies, one cause of AF recurrence after catheter ablation has been faulty reconnection and gaps of PV isolation. ${ }^{29,30}$ Therefore, confirmation of PV isolation and additional ablation by electrophysiologic study after surgical ablation is expected to improve outcomes with minimal adverse effects, especially in longstanding persistent AF.

Our study has several limitations. The first is the small number of patients at a single center, which could result in bias and incomplete data, impairing the generalizability of our results. Second, 12-lead ECG and 24-hour Holter monitoring are less effective in detecting asymptomatic atrial arrhythmia compared with implantable loop recording systems, and thus the rate of arrhythmia recurrence may have been underestimated. Third, in patients with $\mathrm{AF}$ at baseline and with a successful ablation procedure, echocardiographic measurements were obtained during $\mathrm{AF}$ at baseline and sinus rhythm at follow-up, possibly introducing noise in the estimation of actual changes.

To summarize, TTA was effective in restoring LV function and sinus rhythm in our cohort of AF patients with LV dysfunction. The complications related to TTA were reversible and not expected to adversely affect prognosis. Where suitably trained thoracoscopic surgeons are available, TTA should be considered as an alternative or adjunct 
to catheter ablation to improve outcomes related to recurrent $\mathrm{AF}$ in patients with $\mathrm{LV}$ dysfunction.

\section{Conflict of Interest Statement}

The authors reported no conflicts of interest.

The Journal policy requires editors and reviewers to disclose conflicts of interest and to decline handling or reviewing manuscripts for which they may have a conflict of interest. The editors and reviewers of this article have no conflicts of interest.

\section{References}

1. Chiang CE, Naditch-Brûlé L, Murin J, Goethals M, Inoue H, O’Neill J, et al. Distribution and risk profile of paroxysmal, persistent, and permanent atrial fibrillation in routine clinical practice: insight from the real-life global survey evaluating patients with atrial fibrillation international registry. Circ Arrhythm Electrophysiol. 2012;5:632-9.

2. van Deursen VM, Urso R, Laroche C, Damman K, Dahlström U, Tavazzi L, et al. Co-morbidities in patients with heart failure: an analysis of the European Heart Failure Pilot Survey. Eur J Heart Fail. 2014;16:103-11.

3. Maisel WH, Stevenson LW. Atrial fibrillation in heart failure: epidemiology, pathophysiology, and rationale for therapy. Am J Cardiol. 2003;91:2D-8D.

4. Wang TJ, Larson MG, Levy D, Vasan RS, Leip EP, Wolf PA, et al. Temporal relations of atrial fibrillation and congestive heart failure and their joint influence on mortality: the Framingham Heart Study. Circulation. 2003;107:2920-5.

5. Pedersen OD, Bagger H, Keller N, Marchant B, Køber L, Torp-Pedersen C. Efficacy of dofetilide in the treatment of atrial fibrillation-flutter in patients with reduced left ventricular function: a Danish investigations of arrhythmia and mortality on dofetilide (diamond) substudy. Circulation. 2001;104:292-6.

6. Hindricks G, Potpara T, Dagres N, Arbelo E, Bax JJ, Blomström-Lundqvist C, et al. 2020 ESC guidelines for the diagnosis and management of atrial fibrillation developed in collaboration with the European Association of Cardio-Thoracic Surgery (EACTS). Eur Heart J. 2020;42:373-498.

7. Badhwar V, Rankin JS, Damiano RJ Jr, Gillinov AM, Bakaeen FG, Edgerton JR, et al. The Society of Thoracic Surgeons 2017 clinical practice guidelines for the surgical treatment of atrial fibrillation. Ann Thorac Surg. 2017;103:329-41.

8. Calkins H, Hindricks G, Cappato R, Kim YH, Saad EB, Aguinaga L, et al. 2017 HRS/EHRA/ECAS/APHRS/SOLAECE expert consensus statement on catheter and surgical ablation of atrial fibrillation. Heart Rhythm. 2017;14:e275-444.

9. Vos LM, Kotecha D, Geuzebroek GSC, Hofman FN, van Boven WJP, Kelder J, et al. Totally thoracoscopic ablation for atrial fibrillation: a systematic safety analysis. Europace. 2018;20:1790-7.

10. Boersma LVA, Castella M, van Boven W, Berruezo A, Yilmaz A, Nadal M, et al. Atrial fibrillation catheter ablation versus surgical ablation treatment (FAST): a 2-center randomized clinical trial. Circulation. 2012;125:23-30.

11. van Laar C, Kelder J, van Putte BP. The totally thoracoscopic maze procedure for the treatment of atrial fibrillation. Interact Cardiovasc Thorac Surg. 2017;24: 102-11.

12. Calkins H, Kuck KH, Cappato R, Brugada J, Camm AJ, Chen SA, et al. 2012 HRS/EHRA/ECAS expert consensus statement on catheter and surgical ablation of atrial fibrillation: recommendations for patient selection, procedural techniques, patient management and follow-up, definitions, endpoints, and research trial design. Europace. 2012;14:528-606.

13. Stulak JM, Dearani JA, Daly RC, Zehr KJ, Sundt TM III, Schaff HV. Left ventricular dysfunction in atrial fibrillation: restoration of sinus rhythm by the Cox-maze procedure significantly improves systolic function and functional status. Ann Thorac Surg. 2006;82:494-500; discussion 500-501.
14. Ad N, Henry L, Hunt S. The impact of surgical ablation in patients with low ejection fraction, heart failure, and atrial fibrillation. Eur J Cardiothorac Surg. 2011; 40:70-6.

15. Adademir T, Khiabani AJ, Schill MR, Sinn LA, Schuessler RB, Moon MR, et al Surgical ablation of atrial fibrillation in patients with tachycardia-induced cardiomyopathy. Ann Thorac Surg. 2019;108:443-50.

16. Tsang TSM, Barnes ME, Gersh BJ, Bailey KR, Seward JB. Risks for atrial fibrillation and congestive heart failure in patients $>/=65$ years of age with abnormal left ventricular diastolic relaxation. Am J Cardiol. 2004;93:54-8.

17. Daoud EG, Weiss R, Bahu M, Knight BP, Bogun F, Goyal R, et al. Effect of an irregular ventricular rhythm on cardiac output. Am J Cardiol. 1996;78:1433-6.

18. Sairaku A, Nakano Y, Oda N, Uchimura Y, Tokuyama T, Kawazoe H, et al Incomplete cure of tachycardia-induced cardiomyopathy secondary to rapid atrial fibrillation by heart rate control without sinus conversion. J Cardiovasc Electrophysiol. 2014;25:1037-43.

19. Hoit BD, Shao Y, Tsai LM, Patel R, Gabel M, Walsh RA. Altered left atrial compliance after atrial appendectomy. Influence on left atrial and ventricular filling. Circ Res. 1993;72:167-75.

20. Phan QT, Shin SY, Cho IS, Lee WS, Won H, Sharmin S, et al. Impact of left atrial appendage closure on cardiac functional and structural remodeling: a differencein-difference analysis of propensity score matched samples. Cardiol J. 2019;26: 519-28.

21. Haldar S, Khan HR, Boyalla V, Kralj-Hans I, Jones S, Lord J, et al. Catheter ablation vs. thoracoscopic surgical ablation in long-standing persistent atrial fibrillation: CASA-AF randomized controlled trial. Eur Heart J. 2020;41: 4471-80.

22. Janusauskas V, Puodziukaite L, Maneikiene VV, Zuoziene G, Radauskaite G, Burneikaite $\mathrm{G}$, et al. Long-term results of minimally invasive stand-alone biatrial surgical ablation with a bipolar ablation device for persistent and longstanding persistent AF: a single-center case series of 91 patients. J Cardiothorac Surg. 2016;11:23.

23. Saini A, Hu YL, Kasirajan V, Han FT, Khan MZ, Wolfe L, et al. Long-term outcomes of minimally invasive surgical ablation for atrial fibrillation: a singlecenter experience. Heart Rhythm. 2017;14:1281-8.

24. De Maat GE, Pozzoli A, Scholten MF, Van Gelder IC, Blaauw Y, Mulder BA, et al. Long-term results of surgical minimally invasive pulmonary vein isolation for paroxysmal lone atrial fibrillation. Europace. 2015;17:747-52.

25. Maesen B, Pison L, Vroomen M, Luermans JG, Vernooy K, Maessen JG, et al. Three-year follow-up of hybrid ablation for atrial fibrillation. Eur J Cardiothorac Surg. 2018;53(Suppl_1):i26-32.

26. Vos LM, Bentala M, Geuzebroek GS, Molhoek SG, van Putte BP. Long-term outcome after totally thoracoscopic ablation for atrial fibrillation. J Cardiovasc Electrophysiol. 2020;31:40-5.

27. Hwang JK, Jeong DS, Gwag HB, Park KM, Ahn J, Carriere K, et al. Staged hybrid procedure versus radiofrequency catheter ablation in the treatment of atrial fibrillation. PLoS One. 2018;13:e0205431.

28. Lee JW, Choo SJ, Kim KI, Song JK, Kang DH, Song JM, et al. Atrial fibrillation surgery simplified with cryoablation to improve left atrial function. Ann Thorac Surg. 2001;72:1479-83.

29. Solheim E, Hoff PI, Off MK, Ohm OJ, Chen J. Significance of late recurrence of atrial fibrillation during long-term follow-up after pulmonary vein isolation. Pacing Clin Electrophysiol. 2007;30(Suppl 1):S108-11.

30. Darby AE. Recurrent atrial fibrillation after catheter ablation: considerations for repeat ablation and strategies to optimize success. J Atr Fibrillation. 2016;9: 1427.

Key Words: totally thoracoscopic ablation, surgical ablation, atrial fibrillation, heart failure, left ventricular dysfunction, catheter ablation 